\title{
A influência das campanhas nas eleições presidenciais

\author{
O papel da mídia
}

\section{The campaigns' influence in presidential elections \\ The role of media}

Felipe Borba*

\begin{abstract}
Resumo: A importância das campanhas eleitorais reside no fato de que se trata do momento privilegiado da relação entre os cidadãos e a política. É a hora em que as diferentes opções informam à sociedade sobre seu programa de governo, as principais medidas que pretendem impulsionar e que idéias estão por trás destas medidas. A pergunta é: são as campanhas capazes de afetar a percepção dos eleitores? O objetivo deste artigo é o de investigar o grau de influência das campanhas eleitorais na decisão do voto. A análise é restrita a apenas um segmento das campanhas, a cobertura eleitoral feita pelos jornais brasileiros, no contexto das eleições presidenciais de 2002. O artigo inicia com uma discussão a respeito da relação teórica entre eleitores e mídia nos momentos eleitorais. Em seguida, analisa o impacto da cobertura sobre a intenção de voto a partir de um critério que mede o tom das críticas por meio do saldo das matérias positivas e negativas publicadas durante a campanha. Concluímos, com base na aplicação de métodos descritivos e estatísticos, que o voto dado ao candidato Lula (PT) foi fortemente influenciado pela cobertura feita pelos jornais.
\end{abstract}

Palavras-chave: Campanha; Eleições; Mídia

Abstract: The importance of electoral campaigns is due to the fact that they are a privileged moment in the relationship between citizens and politics. It is the moment during which the different political competitors present their proposals, their intended actions, and the main ideas behind them to society. The question is: can campaigns effectively affect the perception of voters? This article investigates the extent of the impact of electoral campaigns on voting decisions. The analysis has been restricted to a single portion of campaigns, the journalistic coverage made by Brazilian newspapers, during the 2002 presidential elections. The article starts with a discussion of the theoretical relationship between voters and the media. It then assesses the impact of coverage on voting decisions according to a criterion that gauges de tone of criticism based on the overall sum of favorable (positive) and unfavorable (negative) pieces published during the campaign. Based on the application of statistical and descriptive methods, it reaches the conclusion that votes for presidential candidate Luiz Inácio Lula da Silva, who ran for the Workers' Party (PT), were heavily influenced by newspaper media coverage.

Key words: Campaigns; Elections; Media

* Doutorando em Ciência Política, pesquisador do Doxa/Iuperj, Rio de Janeiro, Brasil. <fborba@terra.com.br>

\begin{tabular}{|l|l|l|l|l|l|}
\hline Civitas & Porto Alegre & v. 8 & n. 2 & p. 300-322 & maio-ago. 2008 \\
\hline
\end{tabular}




\section{Introdução}

Existe, na literatura política moderna, controvérsia sobre os efeitos da campanha eleitoral no comportamento dos eleitores e no resultado das eleições. $\mathrm{O}$ debate sobre os processos eleitorais encontra-se dividido entre duas perspectivas opostas. Uma longa tradição de estudos encontrou evidências segundo as quais o resultado das eleições pode ser facilmente previsto sem considerarmos os efeitos da campanha política. Nesta linha de investigação, conhecida como "efeitos mínimos", os eleitores decidem em quem votar segundo variáveis políticas e sociais de longo prazo e por meio do julgamento do desempenho administrativo do governante (Lazarsfeld, 1944; Downs, 1957; Campbell, 1960).

Relativamente recente são os estudos que procuram demonstrar os efeitos persuasivos das campanhas eleitorais na definição do voto. Os defensores desta corrente argumentam que as teorias baseadas nos chamados "efeitos mínimos" foram realizadas antes de a televisão chegar a ter uma influência decisiva na política moderna (Comstock, 2005), influência que se viu reforçada diante do fenômeno do desalinhamento partidário, verificado, sobretudo, nas democracias desenvolvidas da Europa e Estados Unidos, nas quais as características dos candidatos e os issues de campanha passaram a ter um peso preponderante (Wattenberg, 1991; Dalton, 2000). Para esta linha, a volatilidade da opinião pública no ano eleitoral seria a evidência empírica a atestar o poderio das campanhas na orientação do voto (Holbrook, 1996).

Analisar o impacto das campanhas sobre a escolha eleitoral constitui, portanto, uma questão politicamente relevante e metodologicamente complexa. É politicamente relevante porque seu pressuposto teórico, o fato de que os acontecimentos políticos alteram a decisão do voto, precisa ser analisado em perspectivas com as variáveis de longo prazo dos eleitores. É metodologicamente complexa porque o teste desta hipótese necessita de demonstrações empíricas válidas, métodos que justifiquem que fatores devem ser analisados e que sejam eficientes no momento de apurar seus impactos sobre o voto.

Este artigo pretende contribuir para o conhecimento dos efeitos das campanhas na decisão do voto. Restringimos a análise a apenas um seguimento das campanhas, a cobertura eleitoral feita pelos jornais brasileiros, no contexto das eleições presidenciais de 2002. Esta decisão tem a ver com a idéia difundida de que a mídia exerce influência decisiva nos processos eleitorais, dado o elevado grau de difusão dos meios de comunicação de massa e da vasta penetração destes veículos na sociedade brasileira. 
Visando oferecer um quadro de referências para a discussão, o artigo debate primeiro o contexto teórico em que se dá a relação entre eleitores e mídia nos momentos eleitorais. Em seguida, trata de analisar o impacto da cobertura eleitoral feita pelos jornais sobre a intenção de voto a partir de um critério que busca medir o tom das críticas por meio do saldo das matérias positivas e negativas publicadas durante a campanha. A hipótese contida no argumento é a de que, num cenário crítico positivo, a tendência é o candidato obter número maior de votos do que num ambiente de aguda crítica jornalística. A campanha analisada é a de Luiz Inácio Lula da Silva (PT), o candidato vencedor nesta eleição presidencial.

\section{Os estudos das campanhas eleitorais}

Numerosos autores têm se dedicado à tarefa de entender os efeitos das campanhas na decisão do voto dos eleitores. A origem desses estudos se encontra na obra de Walter Lippmann, Public opinion, publicada em 1922, na qual o autor atribui enorme capacidade de persuasão à propaganda. Para Lippmann, o poder dos meios de comunicação, no caso a imprensa, o rádio e o cinema, de influir no juízo das pessoas residia no fato de que somente através deles os cidadãos poderiam se informar acerca de uma série de acontecimentos e experiências que de outro modo jamais poderiam tomar conhecimento. Os cidadãos estariam, portanto, sujeitos à manipulação de toda ordem, o que jogava por terra a teoria democrática do cidadão ideal.

É importante ressaltar que os achados de Lippmann foram feitos sem nenhuma análise sistemática sobre os efeitos da propaganda no comportamento dos indivíduos. Lippmann chega a esta conclusão baseado nas observações que fizera no decorrer da Primeira Guerra Mundial, quando escreve sob o impacto das técnicas de propaganda adotadas pelos países envolvidos no conflito. Apesar desta deficiência metodológica, as idéias de Lippmann serviram, por muito tempo, como principal guia dos estudos sobre efeitos da campanha, a ponto de sua teoria ficar conhecida como teoria da "agulha hipodérmica", a idéia segundo a qual a propaganda tem a força de injetar novas atitudes na conduta das pessoas, crença que se viu reforçada diante das máquinas propagandísticas utilizadas pelos regimes autoritários do período entreguerras, que robusteceram ainda mais a sensação de que os meios de comunicação de massa exerciam impacto decisivo sobre a opinião pública e, em última instância, sobre o voto.

Somente em 1944 aparece a primeira investigação sistemática sobre os efeitos da campanha política no comportamento eleitoral. Neste ano, Paul 
Lazarsfeld, Bernard Berelson e Hazel Gaudet publicam The people's choice, obra que teve por objetivo examinar a influência da campanha presidencial norte-americana de 1940. No estudo, os autores tomam o condado de Erie como amostra, por considerá-lo arquétipo, e aplicam invento metodológico chamado panel, que consiste na obtenção de dados a partir de entrevistas repetidas com os mesmos indivíduos em momentos distintos da campanha. Uma das principais conclusões do estudo era de que as teorias da propaganda haviam exagerado muito o poder de persuasão das campanhas.

Lazarsfeld e colegas concluem que a campanha política serve a três propósitos: "ativar" o interesse daqueles para quem a política era indiferente, "reforçar" a intenção daqueles com inclinações políticas e, por último, "converter" os indecisos. Os autores, no entanto, advertem que o efeito quantitativo mais importante das campanhas é reforçar as predisposições dos cidadãos. O efeito de conversão (mudança de voto) foi considerado estatisticamente pequeno, atingindo apenas $8 \%$ da amostra pesquisada, num universo em que $53 \%$ dos pesquisados utilizaram as informações dos meios de comunicação apenas com a finalidade de reforço.

Para os autores, o efeito de reforço é considerado o mais efetivo uma vez que a campanha opera no interior de um grupo de influências que são mais poderosas do que a mídia na criação de atitudes, crença e comportamentos. Segundo este enfoque, as pessoas possuem uma série de predisposições políticas, fundadas especialmente em seus traços socio-demográficos, que não gostam que sejam questionadas. O resultado é a tendência dos indivíduos a exporem-se seletivamente às mensagens que estão em consonância com suas predisposições, mensagens que não desafiam suas crenças de longo prazo. Daí o surgimento da expressão "efeitos mínimos", denominação cunhada para designar toda a corrente de pensamento para a qual o impacto da mídia era mínimo.

A importância dos partidos políticos é fundamental para compreender a evolução dos estudos sobre os efeitos de campanha. Os pesquisadores posteriores que adotaram a perspectiva dos "efeitos mínimos" destacam a identificação partidária como principal orientadora do voto. Campbell e colegas, na obra The American voter (1960), argumentam que os indivíduos estabelecem laços afetivos com os partidos, laços construídos no processo de socialização, e seguem votando neste partido repetidas vezes ao longo de sua trajetória histórica. Para os autores, o partido funciona como um atalho cognitivo e serve tão apenas para ajudar na escolha eleitoral, mas serve, sobretudo, como guia que orienta a percepção sobre candidatos e issues de campanha. 
Do mesmo modo, Anthony Downs (1957), precursor da teoria da escolha racional, também defende a tese da centralidade dos partidos na vida política. Só que, ao contrário da escola psicológica de Michigan, para quem a afinidade partidária é função de valores político-sociais, Downs enxerga a preferência partidária como um atalho que simplifica o processo de decisão eleitoral. No seu argumento, o eleitor, em vez de ter o custo de se manter inteirado sobre uma gama de assuntos, mantém vínculo com o partido no qual acredita proporcionará os maiores benefícios sob os menores custos - e segue votando nele em repetidas eleições, a não ser em ocasiões especiais, nas quais decide mudar o voto para o partido adversário.

Ademais, os autores da perspectiva da teoria racional salientavam que o fator decisivo na escolha política era o julgamento retrospectivo da capacidade administrativa do governante. O julgamento retrospectivo baseiase na premissa segundo a qual cada eleitor age em resposta ao que percebe e experimenta em relação às condições do país, punindo ou premiando os partidos de acordo com suas atuações, como se fosse um juiz (Downs, 1957; Key, 1966; Fiorina, 1981). Nestas condições, as campanhas eleitorais teriam função secundária na decisão do voto, funcionando apenas como veículos utilizados pelos partidos a fim de informar o eleitorado a respeito das políticas em marcha no país.

A aparição de uma nova perspectiva, que confere papel relevante às campanhas eleitorais, está relacionada a uma série de transformações históricas que afetam o modo como os eleitores se relacionam com a política. Comstock (2005) destaca como relevantes o declínio do papel dos partidos e o desenvolvimento das modernas técnicas de comunicação de massa, especialmente a televisão, como as principais variáveis deste processo. Em essência, o argumento é o de que a decadência dos partidos teria promovido sua substituição, como agente privilegiado na formação da opinião pública e na definição do voto, pela a mídia e, por extensão, pelas campanhas nos momentos eleitorais.

Com efeito, o argumento de Comstock parece bem convincente. Se os partidos nasceram como intermediários privilegiados na relação entre estado e sociedade, consolidando-se como principais atores políticos em sistemas democráticos, é de se esperar que o declínio dos mesmos abra espaço para que outras instituições auxiliem os indivíduos no processo de orientação das atitudes políticas e no processo de definição do voto. ${ }^{1}$ Este argumento

As razões para o declínio dos partidos são muitas, entre elas o próprio desenvolvimento da televisão. Dalton destaca ainda o aumento do nível educacional dos indivíduos modernos, a erosão das clivagens sociais, o surgimento de grupos de interesse como as ONGs e as modernas técnicas de campanha eleitoral. Para discussão mais detalhada sobre o assunto, consultar Dalton (2000). 
é ainda mais plausível se considerarmos que a televisão possui uma série de atributos que a capacita a assumir o papel de formador de opinião que antes cabia aos partidos.

Comstock argumenta que a contribuição mais significativa da televisão foi a de expandir a capacidade de alcance da mídia. O autor observa que a televisão atinge atualmente cerca de $98 \%$ dos domicílios americanos, percentual que considera o limite da saturação. No Brasil, a realidade é bem parecida. Dados do IBGE, levantados na Pnad 2002, revelam que $90 \%$ dos domicílios brasileiros possuem televisores. Tão importante quanto o alcance, destaca o autor, é o formato e a estrutura das mensagens. A televisão sobressai frente aos demais veículos de comunicação porque apresenta noticiário mais acessível e mais interessante, por meio principalmente de imagens e estórias em formato de drama, o que facilita a compreensão especialmente para as pessoas com escassos recursos cognitivos, que de outra maneira considerariam o conteúdo das notícias opaco e teriam de recorrer aos líderes de opinião.

O autor destaca que a força da televisão como modeladora da opinião pública advém de sua credibilidade. Comstock é de opinião de que a televisão supera os partidos em confiabilidade em função de três fatores. Em primeiro lugar, os apresentadores e repórteres televisivos gozam de extrema credibilidade e popularidade, características não atribuídas à maioria dos políticos. Em segundo lugar, a televisão oferece imagens que comprovam a veracidade do fato noticiado. Por último, o caráter imediato e simplista da apresentação das notícias, o que diminuiu o risco de erro.

Em relação às campanhas eleitorais, Comstock argumenta que a televisão é importante porque permitiu o desenvolvimento dos spots eleitorais, comerciais de 30 segundos que os partidos financiam no meio da programação normal da emissora. A importância dos spots é que eles solapam o filtro por meio dos quais as pessoas se protegem de informações políticas que desafiam suas predisposições de longo prazo, tarefa que era muito fácil de realizar com as mensagens contidas nos jornais impressos, como bem salientou Lazarsfeld em seu clássico estudo. O fato de a televisão ser atualmente o principal gasto dos comitês eleitorais é a evidência contundente da eficácia deste instrumento na captação de votos, completa o autor.

Ademais, a influência das campanhas na decisão do voto pode ser observada com base no acompanhamento da evolução da opinião pública durante ano eleitoral. Thomas Holbrook (1996) argumenta que os pontos de inflexão nas curvas de intenção de voto são as principais evidências de que as intervenções provocadas pela ação dos candidatos produzem 
alterações no comportamento da opinião pública. Em outras palavras, o que o autor pretende dizer é que a volatilidade do eleitorado, em relação ao nível de apoio às candidaturas, reflete o sucesso relativo dos candidatos em persuadir os eleitores.

\section{Um modelo para o estudo das campanhas}

Para investigar o impacto das campanhas eleitorais na opinião pública, usamos como método de análise o modelo proposto por Thomas M. Holbrook. No livro Do campaigns matter? (1996), Holbrook propõe um modelo de análise das campanhas que investiga o processo de informação. No seu argumento, uma campanha só é capaz de influenciar a opinião pública por meio da disseminação de informações que os eleitores consomem e utilizam para decidir em quem votar.

Holbrook defende que o processo de informação que melhor se adapta aos propósitos de sua tese é o modelo online de avaliação dos candidatos. De acordo com esse modelo, os eleitores começam a campanha com uma impressão geral dos candidatos. À medida que as informações são geradas e divulgadas, é esperado que elas provoquem mudanças na avaliação que os eleitores fazem dos candidatos e gerem, por conseqüência, melhora nos níveis de aceitação do político favorecido - ou piora, caso a informação seja negativa. O modelo se chama online uma vez que o monitoramento das informações acontece em tempo real e seu processamento é de caráter imediato.

O modelo de Holbrook é composto por três variáveis: os eventos de campanha, a mídia e a condição nacional do país. Essas variáveis interagem e são responsáveis pela geração e propagação das informações que causam a volatilidade da opinião pública e interferem no resultado das eleições. Em outras palavras, os eventos de campanha, a cobertura jornalística e a condição nacional do país são as variáveis independentes do modelo, enquanto o índice de intenção de votos é a variável dependente.

No seu modelo, Holbrook considera como eventos de campanha as convenções partidárias e os debates eleitorais. Segundo o teórico, esses dois eventos são importantes por fornecerem informações para os eleitores decidirem o voto. A principal função de uma convenção partidária é produzir a imagem do candidato e do partido alguns meses antes das eleições. Na convenção, os partidos apresentam seus candidatos, seus objetivos e sua plataforma de governo para o eleitor ainda desinformado. 
O que é importante destacar é que as convenções partidárias garantem audiência exclusiva sobre o candidato num período em que a capacidade de influenciar os eleitores é maior. Segundo Holbrook, as convenções acontecem num momento em que a quantidade de informações sobre os candidatos é escassa e o aumento do fluxo de informações, garantido, sobretudo, pela cobertura jornalística, atinge os eleitores quando eles ainda apresentam apenas uma impressão sobre os candidatos. A conseqüência é a elevação imediata dos índices de intenção de voto.

Do mesmo modo, os debates políticos são importantes numa campanha eleitoral como fonte de informação para os eleitores. De acordo com Holbrook, o formato dos debates atuais, nos quais os concorrentes são apresentados lado a lado, possibilitam a comparação direta entre as propostas de governo e, principalmente, o estilo pessoal de cada candidato. Além disso, os debates são importantes por causa da repercussão que geram. No dia seguinte, é comum os principais veículos de comunicação apontarem o candidato que saiu "vitorioso" da disputa. Este tipo de informação é valiosa na medida em que pode influenciar os eleitores ainda indecisos.

Seguindo o argumento de Holbrook, a mídia exerce duas funções essenciais na distribuição da intenção de voto. Além da tarefa de divulgar os eventos de campanha que não são diretamente presenciados pelos eleitores, a mídia gera fatos de campanha contra os quais os candidatos precisam reagir. Mais do que isso, e que é importante destacar para os propósitos desta argumentação, a mídia pode usar critérios de noticiabilidade que terminam por beneficiar determinados candidatos em detrimento dos outros, seja por aspectos quantitativos (visibilidade) ou qualitativos (valência).

Por último, a condição nacional do país funciona como fator de inibição da persuasão política. Este limite é resultado das condições políticas, econômicas e sociais vigentes. Segundo o autor, cada eleição está inserida num contexto de acordo com o qual os eleitores estão predispostos inicialmente. Num cenário de crescimento econômico, baixo desemprego e alta popularidade do presidente, a tendência é a de o eleitorado direcionar sua preferência para o candidato do governo, independente do partido, o que inibe a ação eleitoral e persuasiva da oposição.

O modelo de Holbrook, desenhado para investigar as eleições norteamericanas, precisaria ser modificado em vários aspectos para dar conta da experiência eleitoral brasileira. A primeira modificação é ampliar a noção de eventos de campanha e incluir a propaganda eleitoral como variável significativa na decisão do voto. Este problema é particularmente interessante 
para o caso brasileiro devido às características do horário gratuito de propaganda eleitoral (HGPE).

O modelo de propaganda política na televisão distingue-se, em muitos aspectos, daqueles adotados por outros países. Segundo Afonso de Albuquerque (1999), a propaganda política brasileira desempenha um papel tão central nas campanhas políticas por combinar o acesso gratuito dos partidos à televisão (e a proibição da propaganda política paga) com relativa desregulamentação do conteúdo veiculado, embora a regulamentação varie de eleição para eleição, com graus diversos de liberdade criativa. Uma questão central do modelo brasileiro de propaganda na televisão é a de que as transmissões políticas são feitas em horário fixo, uma vez no turno da manhã e outra no turno da tarde, em todas as emissoras da televisão aberta. Esta peculiaridade, embora constitua uma ruptura com a programação normal das emissoras e seja vista por muitos telespectadores como uma invasão arbitrária de uma programação já legitimada pelo hábito, possibilita, por outro lado, que o eleitor saiba quando e onde buscar informações de baixíssimo custo sobre os candidatos.

A imposição pela legislação eleitoral do período de exibição da propaganda e do tempo destinado a cada partido traz, ainda, duas conseqüências às quais os candidatos precisam adaptar suas necessidades. Em primeiro lugar, a fixação do período de exibição para os últimos dias do ano eleitoral dificulta o grau de controle sobre o ritmo da campanha, além de impedir a transmissão de mensagens para um público-alvo específico. As mensagens alcançam os eleitores que por acaso estejam sintonizados no momento da sua transmissão. Em segundo lugar, o preenchimento do horário a que cada partido tem direito constitui, muitas vezes, um problema, seja pelo escasso tempo para transmitir mensagens consistentes, seja porque o tempo é longo demais para os recursos do candidato.

A segunda alteração no modelo de Holbrook diz respeito à importância das convenções partidárias. No Brasil, não devemos esperar que elas causem impacto na opinião pública com a mesma intensidade que ocorre nos Estados Unidos. Apontamos três razões básicas para justificar a perda de influência das convenções partidárias: o pequeno período destinado às suas realizações, o número excessivo de convenções e a escassa cobertura jornalística.

O artigo oitavo da Lei Eleitoral 9.504, que regulamenta as convenções partidárias desde setembro de 1997, determina que as convenções devem ser feitas no período entre 10 e 30 de junho do ano eleitoral. O que daí se segue é que o curto espaço de tempo e o número excessivo de convenções que acontecem ao mesmo tempo, tanto no nível nacional quanto no nível 
estadual, impedem que um candidato tenha aumento de visibilidade exclusiva em decorrência da cobertura jornalística e a elevação imediata dos índices de intenção de votos. Em outras palavras, durante a realização das convenções, a mídia divide o noticiário entre muitos partidos e candidatos e o efeito de uma aparição termina por ser anulado pelo efeito de outra aparição. Mais importante do que as duas razões apontadas acima, o que parece melhor explicar a inoperância das convenções como variável explicativa do voto é o baixo interesse da mídia em cobri-las como fato noticiável relevante. A explicação pode ser a falta de novidade que caracteriza o evento. Em geral, as convenções apenas ratificam decisões que foram estabelecidas em acordos políticos pré-eleitorais. De fato, análise da cobertura dos jornais revela que menos de $10 \%$ do noticiário eleitoral publicado no período das convenções se referem a elas.

A terceira alteração procura incluir as propagandas partidárias como variável significativa sobre as curvas de intenção de voto. No Brasil, a legislação eleitoral estabelece que os partidos, no período anterior às convenções, disponham de um tempo para a propaganda político-institucional, sendo vedada qualquer mensagem de caráter eleitoral. O que é importante destacar é que as propagandas destinadas aos partidos devem causar sobre o eleitorado os mesmos efeitos que observamos nas convenções norte-americanas. No Brasil, as propagandas partidárias são importantes ao combinar penetração nacional (com transmissão em rede) e exclusividade. $\mathrm{O}$ calendário eleitoral dilui as apresentações entre janeiro e junho do mesmo ano. Dito de outro modo, os partidos exibem seus programas sem a concorrência dos outros partidos e os eleitores são abastecidos por informações incontestadas. Devemos esperar, portanto, uma elevação nos índices de intenção de voto logo após a veiculação dos programas.

Neste estudo, procuramos analisar com profundidade a influência da cobertura eleitoral sobre os índices de intenção de voto dos candidatos Luiz Inácio Lula da Silva (PT) e José Serra (PSDB), durante as eleições presidenciais de 2002. A decisão de negligenciar as outras variáveis, que Borba (2005) mostrou serem fortes preditores do voto, decorre do intenso debate no qual a sociedade brasileira, em especial o mundo acadêmico, está envolvida sobre o comportamento da imprensa desde as eleições de 1982. Como contrapartida, analisaremos também a condição nacional do país, medida através dos índices de avaliação do governo, e a preferência partidária, com o objetivo de verificar o peso destas variáveis na decisão final do eleitor. 


\section{Metodologia e análise}

Esta seção procura estudar o impacto da mídia na decisão do voto em Lula. A relevância de investigar a mídia decorre do fato de que, nas sociedades contemporâneas, a cobertura jornalística funciona como uma das principais fontes de informação que os eleitores usam para escolha eleitoral (Kleinnijenhuis e Ridder, 1998; Vreese e Semetko, 2004). A hipótese contida nesta premissa é a de que um noticiário negativo pode contribuir para um candidato perder votos, assim como, inversamente, a avaliação de um candidato tende a melhorar quando o eleitorado é confrontado com notícias positivas.

Para avaliar a influência da mídia sobre a decisão eleitoral, usaremos como fonte de análise a cobertura dos jornais Folha de S. Paulo, O Estado de $S$. Paulo e $O$ Globo. A decisão de concentrar o estudo sobre a mídia impressa advém da influência que os jornais exercem sobre o público formador de opinião e da capacidade que esses veículos possuem para pautar o noticiário nacional, principalmente a televisão. Concentraremos a análise sobre estes três jornais, uma vez que eles são os que mais se aproximam de uma idéia de veículo nacional, face ao seu alto grau de penetração.

Neste estudo, tomaremos como base de investigação a metodologia desenvolvida pelo Laboratório de Pesquisas em Comunicação Política e Opinião Pública do Instituto Universitário de Pesquisas do Rio de Janeiro (Doxa/Iuperj), que combina dados sobre visibilidade e valência. Utilizaremos como critério norteador somente a valência das matérias, que procura qualificar o conteúdo das notícias como positivas, negativas ou neutras. Embora o número de citações seja um critério sinalizador de tendências, a cobertura eleitoral de 2002 mostrou ser relativamente homogênea em termos de espaço concedido aos principais candidatos (Aldé, 2003).

Em nosso modelo, procuramos analisar o impacto da imprensa sobre a intenção de voto a partir de um critério que busca medir o tom das críticas, que obtemos por meio do saldo entre o número de citações positivas e negativas. Argumentamos que o tom das críticas funciona como um indicador mais preciso da postura dos jornais em relação aos candidatos. A idéia central é a de que um candidato com saldo positivo tem uma probabilidade maior de receber votos do que um candidato com saldo negativo.

A relação teórica entre as informações da mídia e a decisão do voto funciona de acordo com o modelo online de avaliação dos candidatos. Neste modelo, a intenção de voto ocorre em função de uma série de influências a que o eleitor teve acesso antes de declarar sua preferência. No caso específico 
da mídia, o modelo procura dizer que a ção de voto no momento $\mathrm{t}+1$ será de acordo com o tom da crítica a que o eleitor esteve exposto depois de declarar voto no momento t. Argumentamos que a chance de o candidato aumentar sua a intenção de voto no momento $\mathrm{t}+1$ é função direta da cobertura da imprensa. Isto é, se o tom do noticiário for positivo, a parcela que declarou voto no momento $t$ tende a permanecer igual ou aumentar. Em caso de tom negativo, a tendência é de a parcela manter-se a mesma ou diminuir.

Com o objetivo de testar o modelo, utilizamos planilha de acompanhamento dos jornais $O$ Globo, Folha de S. Paulo e O Estado de S. Paulo feita pela equipe do Doxa. Dividimos a série temporal segundo as datas das pesquisas eleitorais realizadas pelo Instituto Datafolha. Em seguida, tiramos a média, para cada período, do número de aparições positivas e negativas dos candidatos Lula e José Serra. Por último, para alcançarmos o tom da crítica, subtraímos os valores negativos dos valores positivos. O resultado encontra-se no Gráfico 1 abaixo:

\section{Gráfico 1: Evolução do voto espontâneo em Lula, segundo a crítica dos jornais}

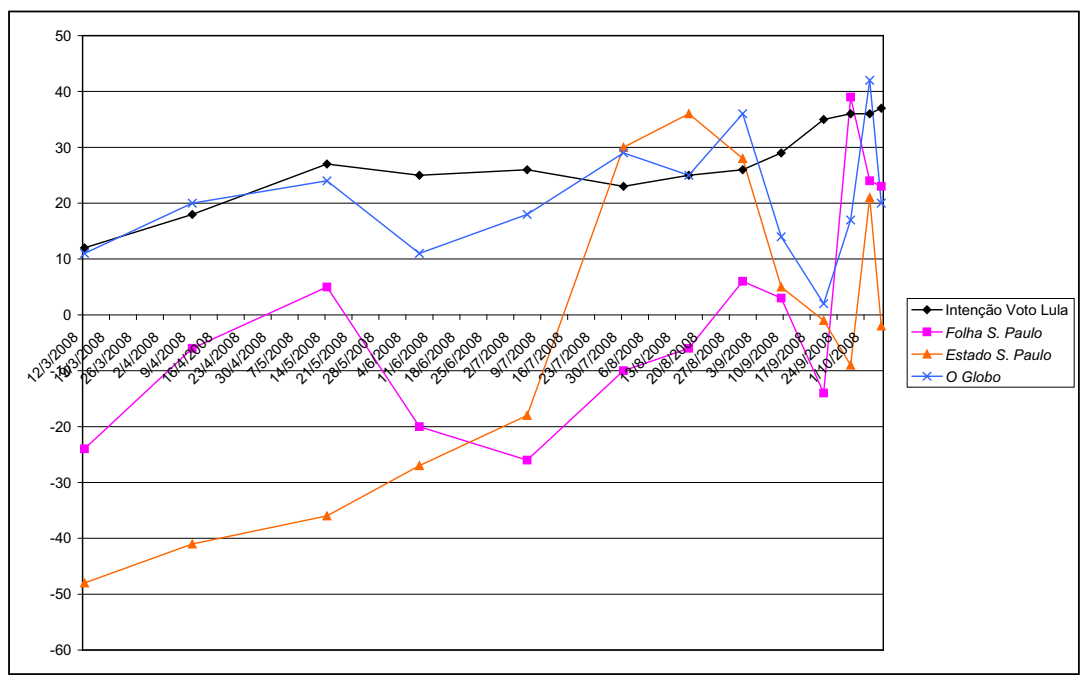

Fonte: Relatórios Datafolha e Planilhas Doxa sobre os jornais O Globo, Folha de S. Paulo e Estado de S. Paulo.

Obs.: As datas se referem aos dias em que o Datafolha fez trabalho de campo sobre a intenção de voto dos candidatos durante a campanha de 2002 . 
O gráfico acima descreve o tom das críticas para os três principais jornais estudados neste artigo. O eixo das categorias, na linha horizontal, divide a área do gráfico em duas metades iguais. A parte de cima representa o saldo positivo dos jornais, enquanto a parte de baixo expõe o saldo negativo. O primeiro exame da evolução das críticas revela que os três jornais tiveram, ao longo de 2002, padrão de comportamento inteiramente distinto uns dos outros. Na análise do Gráfico 1 podemos perceber que $O$ Globo foi um jornal totalmente benevolente em sua cobertura. O saldo da crítica é positivo do início ao fim da campanha. Inversamente, a Folha de S. Paulo foi o veículo mais crítico em relação a Lula. A evolução de sua crítica mostra que seu saldo começa negativo, melhora um pouco no período entre abril e março, para voltar a cair logo depois desta data. Em seguida, o saldo permanece até o final de agosto, quando volta a apresentar, logo em seguida, novo saldo negativo. Apenas no final da campanha, já em setembro, a crítica da Folha passa a tratar Lula de forma positiva.

$O$ Estado de S. Paulo revela comportamento mais intrigante. O jornal paulista inicia a campanha como o mais crítico entre todos. No período de março, o saldo da crítica é de -48 . O jornal, no entanto, vai diminuindo progressivamente o tom de sua crítica até atingir, em cinco de julho, saldo negativo de -18. A partir daí, podemos notar uma inversão em seu comportamento. No período de análise seguinte, em 30 de julho, o saldo é de +30 . $O$ Estado mantém padrão positivo, embora em queda, até 20 de setembro, quando apresenta saldo negativo de -1 . No período seguinte, o saldo ainda é negativo (-9), mas, logo em seguida, volta a tratar Lula positivamente, padrão que vai até o final do primeiro turno.

A análise descritiva não permite efetuarmos, em virtude deste quadro distinto de comportamento, uma conclusão satisfatória sobre os efeitos dos jornais na decisão do voto. Podemos perceber que a evolução do índice de intenção de voto de Lula acompanha, nas primeiras datas, a evolução do tom das críticas dos três jornais. Entre março e maio, é visível que a diminuição do tom das críticas pode ser um dos elementos com impacto sobre o apoio dos eleitores em relação a Lula. A partir deste ponto, no entanto, fica difícil constatarmos qualquer relação entre os três jornais e a curva de intenção de voto. Ao contrário, vemos que os três jornais aumentam o tom de suas críticas, sobretudo após agosto, mas a curva de votos de Lula permanece em progressiva ascensão.

Uma estimativa mais precisa do efeito dos jornais pode ser alcançada se calcularmos o saldo médio da mídia. O objetivo é buscar um indicador único que possa servir com mais precisão para avaliar o impacto da crítica 
jornalística sobre a escolha eleitoral. A hipótese é a de que o saldo médio da mídia dá a exata dimensão do clima editorial que vigorou no país durante as eleições. Dito de outro modo, o saldo médio permite inferir que os demais veículos de comunicação se portaram de forma semelhante, dada a aproximação ideológica entre os grandes conglomerados de mídia brasileiros.

Para chegarmos a este indicador, somamos, para cada período, a média positiva de cada jornal e dividimos este valor por três. Em seguida, repetimos a operação para os valores negativos médios. Por último, subtraímos o valor positivo do valor negativo. O resultado é o saldo médio dos três jornais, que podemos visualizar no Gráfico 2 abaixo:

\section{Gráfico 2: Evolução do voto espontâneo em Lula, segundo saldo médio da mídia}

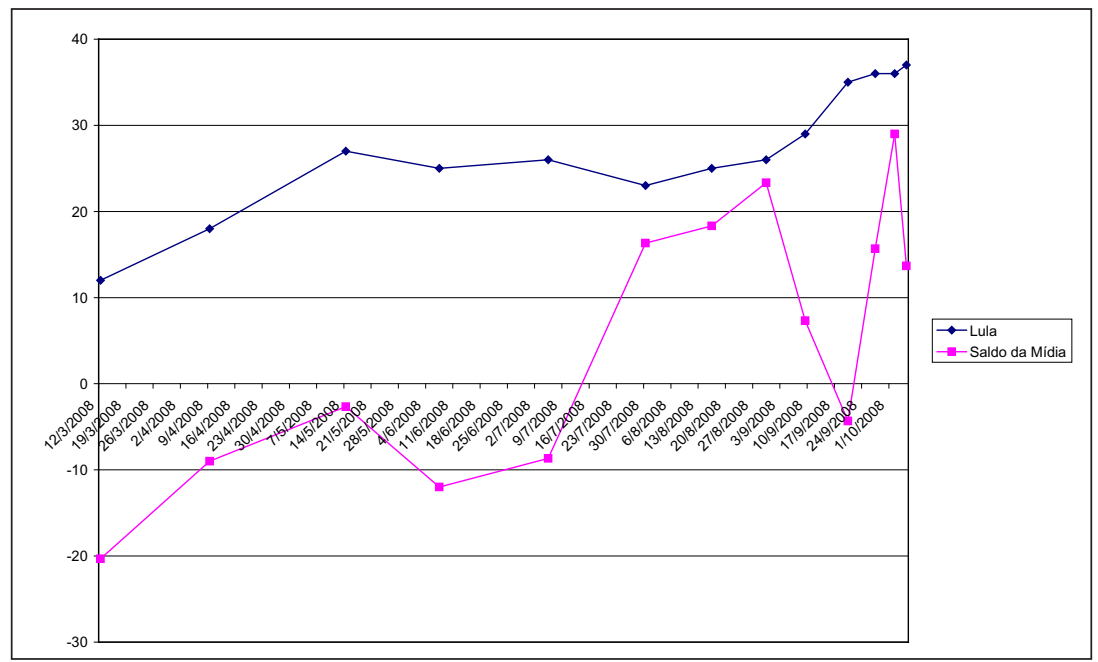

Fonte: Relatórios Datafolha e Planilhas Doxa sobre os jornais O Globo, Folha de S. Paulo e Estado de S. Paulo.

Obs.: As datas se referem aos dias em que o Datafolha fez trabalho de campo sobre a intenção de voto dos candidatos durante a campanha de 2002 .

Pelo acompanhamento do saldo médio da mídia, podemos observar que a sua evolução dividiu-se em dois períodos distintos. No início do ano eleitoral, a cobertura da imprensa foi marcada por aguda crítica ao candidato Lula. Observe-se que, depois do dia 5 de julho, há inversão do comportamento da mídia. O saldo médio, que era profundamente anti-Lula, 
toma forma oposta e o candidato do PT passa a contar com uma imprensa mais disposta a investir numa pauta positiva.

Nesta nova configuração, a relação entre cobertura eleitoral e voto ganha contornos mais nítidos. Pela comparação da evolução das duas linhas do Gráfico, é possível reparar que o índice de voto declarado de Lula acompanha o abrandamento da crítica dos jornais, como sugere a linha de tendência, embora a evolução da crítica seja marcada por alterações profundas. O momento em que esta relação se afigura problemática ocorre no final de agosto, no início do HGPE. Repare que a crítica aumenta até se tornar novamente negativa, mas a evolução dos votos de Lula permanece em ascensão.

Para buscar explicações sobre a curva do saldo médio da mídia, mais precisamente a reviravolta observada em julho, é preciso refrescar a memória acerca dos temas que predominavam na agenda comum dos três jornais. A análise do conteúdo dos jornais revela que a mudança no tratamento com o candidato Lula ocorre após a publicação, por parte do PT, da Carta ao Povo Brasileiro, documento no qual o partido afirma a disposição de manter a política econômica. É a partir de sua aproximação com o establishment, portanto, que o candidato do PT passa a contar com uma imprensa mais interessada em investir numa pauta de caráter positivo.

De fato, até sua aproximação com a linha editorial dos jornais, Lula teve saldo médio de $-10,53$. No período posterior ao do seu acerto de contas com o establishment, seu saldo inverte o sinal e Lula tem média de citações positivas em 14,91. Na ponta do lápis, o saldo da cobertura foi pró-Lula, com média geral de 5,12. Esta constatação nos leva a afastar a hipótese de que o petista conseguiu pautar a imprensa com o trabalho de uma campanha profissionalizada. Em vez disso, podemos constatar que Lula aproximou-se do establishment como resposta política às cobranças que vinha sofrendo sobre a condução da economia em possível governo.

Com base nestas observações, a análise do impacto da campanha sobre o índice de voto em Lula precisa incluir a variável "adesão ao establishment". Com este objetivo, criamos uma dummy na qual codificamos 1 para todos os períodos posteriores a 5 de julho e 0 para todos os períodos anteriores. Os valores obtidos revelam que o saldo da mídia $(b=0,575$, $\mathrm{p}<0,5)$ e a adesão ao establishment $(\mathrm{b}=0,633, \mathrm{p}<0,5)$ são ambos estatisticamente significantes. Recordemos, porém, que a influência da campanha na formação de comportamentos é ponderada por uma série de 
outras variáveis. Em virtude deste fato, recorreremos agora à análise da influência da condição nacional do país e da preferência partidária, que, como dito anteriormente, exercem forte interferência do comportamento dos indivíduos.

\section{A condição nacional do país, a preferência partidária e o voto final em Lula}

Esta seção procura investigar o impacto da condição nacional do Brasil na decisão do voto em Lula, na campanha presidencial de 2002. Como salientado anteriormente, investigar a condição nacional de um país, durante um ano eleitoral, é importante na medida em que ela funciona como fator de inibição da persuasão política. A expectativa é a de que os contextos econômico, social e político de uma eleição afetem o nível de apoio aos candidatos. Se o clima corrente for de prosperidade e satisfação, devemos esperar que o candidato do governo, que representa o status quo, seja beneficiado. Caso contrário, se os eleitores apresentam sinais de insatisfação, a expectativa é a de que o candidato da oposição aumente suas chances de voto.

$\mathrm{Na}$ literatura que investiga o impacto da condição nacional sobre o voto, existem duas dimensões que procuram medir o clima de satisfação dos eleitores: o estado da economia e a avaliação do governante. A primeira dimensão procura estudar o impacto de indicadores econômicos clássicos sobre o voto, sendo os principais a taxa de desemprego, a taxa de crescimento do Produto Interno Bruto (PIB) e a taxa de inflação. Nesta linha, também são usados indicadores de opinião pública, tais como a percepção sobre a situação econômica do país ou percepções individualistas, como a avaliação financeira pessoal.

Neste estudo, a condição nacional do país será medida em função do nível de avaliação do governo Fernando Henrique Cardoso. Em análises deste tipo, o objetivo é usar a popularidade do presidente como termômetro para o ambiente político, econômico e social do país. Usaremos como medida de popularidade o percentual de eleitores que aprova/desaprova o governo Fernando Henrique, segundo medições do Instituto Datafolha referentes apenas ao ano de 2002. A hipótese é a de que a intenção de voto em Lula seja determinada, em razão do seu histórico oposicionista, pelos eleitores que avaliam como ruim ou péssima a administração de Fernando Henrique. O Gráfico 3 mostra as linhas de avaliação: 
Gráfico 3: Evolução da avaliação do governo Fernando Henrique (2002)

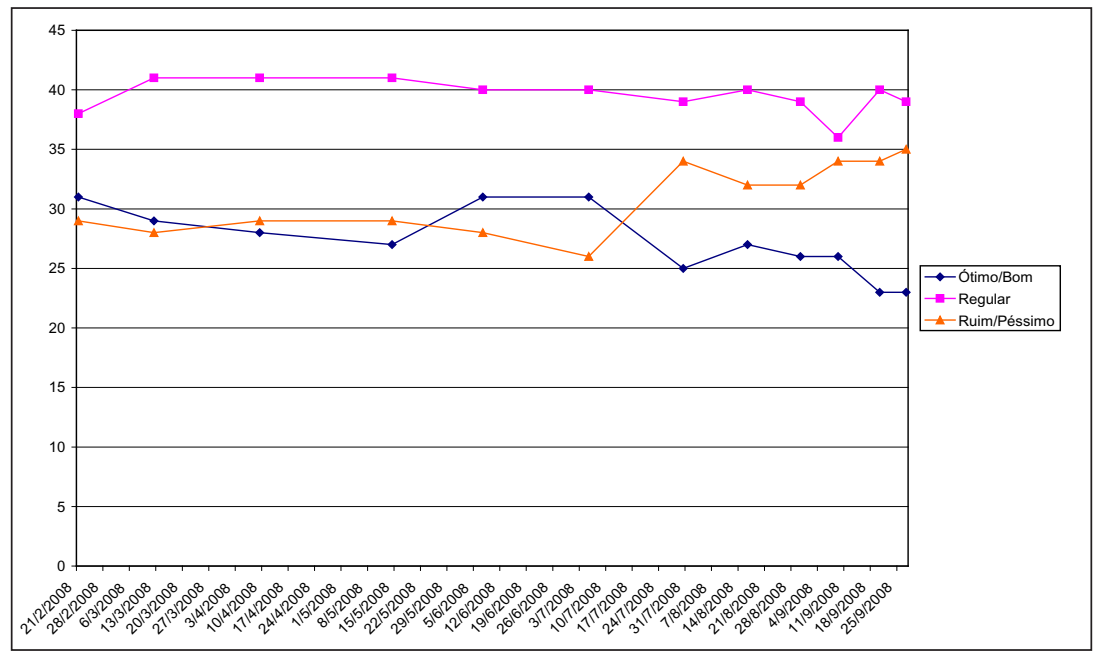

Fonte: Relatórios Datafolha

Obs.: As datas se referem aos dias em que o Datafolha fez trabalho de campo sobre a avaliação do governo Fernando Henrique durante a campanha de 2002.

A análise do gráfico acima revela que o governo Fernando Henrique, no último ano de mandato, foi avaliado como regular pela maior parte do eleitorado, mas atingiu a reta final do primeiro turno com saldo negativo, se levarmos em conta apenas os eleitores que declaram ótimo/bom ou ruim/ péssimo. No começo do ano, os eleitores que avaliavam seu governo como ótimo/bom somavam $31 \%$, contra $29 \%$ que o consideravam ruim/péssimo. À medida que as eleições avançam, no entanto, é possível verificar que os eleitores insatisfeitos ultrapassam o conjunto de eleitores satisfeitos, panorama que se mantém estável até o fim. Na pesquisa de 27 de setembro, última que aferiu a avaliação de governo antes das eleições, Fernando Henrique conta com $35 \%$ de avaliação negativa, enquanto aqueles que gostavam do seu governo eram apenas $23 \%$.

Diante desses números, é possível inferir que os climas político, econômico e social acabaram por beneficiar o candidato da oposição. A evolução das linhas acima mostra claramente que o mote da eleição do sucessor de Fernando Henrique haveria de ser a mudança, como ficou evidenciado no número de candidatos que concorreram à frente de partidos de oposição. Das seis candidaturas, cinco se referiam como opositoras e até 
mesmo o candidato do governo, José Serra, afirmava ter sido desde sempre um crítico da política econômica do governo Fernando Henrique, de quem fora ministro da Saúde.

Não é difícil concluir que o principal beneficiado deste panorama político tenha sido Lula, em função de seu histórico de candidato de oposição que construiu desde 1989, quando concorreu, pela primeira vez, ao cargo de presidente. Este panorama se vê reforçado diante do fato de que Lula perdeu duas eleições para o próprio Fernando Henrique, uma em 1994, outra em 1998, quando este se apoiava em boas avaliações. O Gráfico 4 procura mostrar a correlação entre avaliação negativa de Fernando Henrique e o voto em Lula.

\section{Gráfico 4: Evolução do voto espontâneo em Lula, segundo avaliação negativa de Fernando Henrique (2002)}

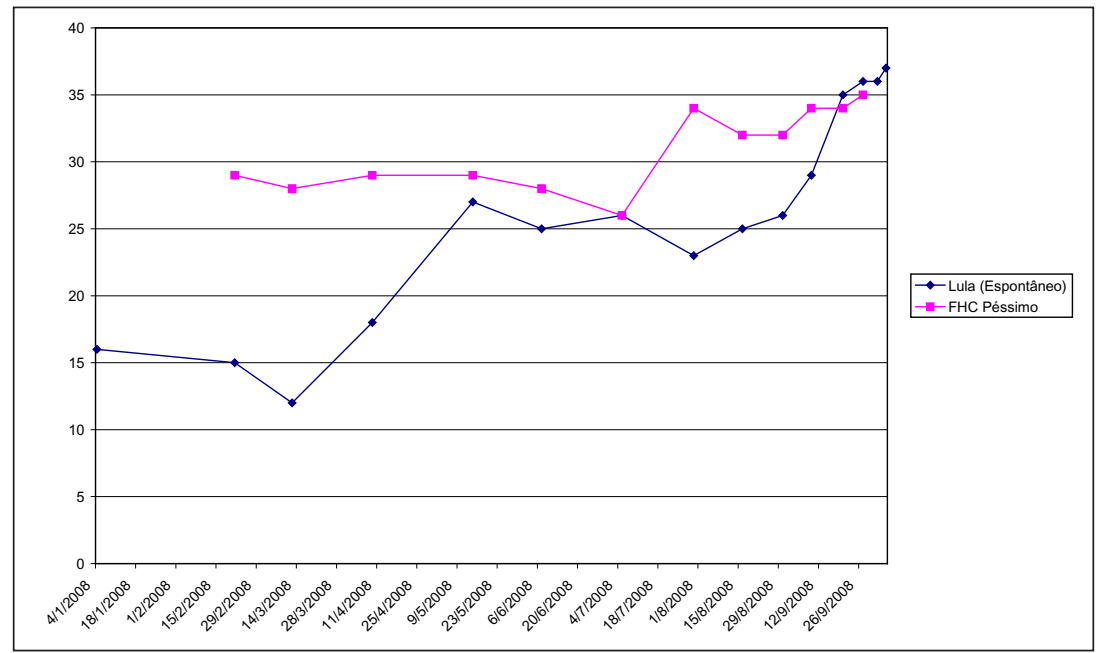

Fonte: Relatórios Datafolha.

Obs.: As datas se referem aos dias em que o Datafolha fez trabalho de campo sobre a intenção de voto dos candidatos durante a campanha de 2002 .

Pelo gráfico acima, podemos analisar que a curva de intenção de voto em Lula é influenciada pela avaliação negativa de Fernando Henrique. Podemos perceber que a evolução espontânea de Lula cresce à medida que a avaliação negativa de Fernando Henrique também aumenta. A relação entre as duas variáveis fica ainda mais clara quando adicionamos a reta de 
tendência. Pela análise da reta, é possível verificar que o índice de voto espontâneo de Lula é positivamente correlacionado com os eleitores que consideram o governo Fernando Henrique ruim ou péssimo. Com efeito, o teste de regressão $(b=0,609, p<0,5)$ atesta a significância do modelo (ver Tabela 2).

Por último, antes de considerarmos a avaliação de governo ao lado da variável campanha, representada aqui pela cobertura da imprensa, precisamos incorporar à análise a variável preferência partidária, se quisermos compreender de modo mais completo como foi a orientação do voto dado a Lula. Neste estudo, apostamos que a identificação partidária funciona como um dos principais componente na decisão do voto, apesar de uma corrente expressiva da ciência política moderna vir detectando perdas sistemáticas nos índices internacionais. A hipótese central é a de que Lula teve seu resultado eleitoral fortemente influenciado pelos eleitores com preferência pelo PT.

Tabela 1: Evolução da preferência partidária durante as eleições de 2002

\begin{tabular}{|c|c|c|c|c|c|c|c|c|c|c|c|c|c|c|}
\hline Partido Data & $4 / 1$ & $21 / 2$ & $12 / 3$ & $9 / 4$ & $14 / 5$ & $7 / 6$ & $5 / 7$ & $30 / 7$ & $16 / 8$ & $30 / 8$ & $9 / 9$ & $20 / 9$ & $27 / 9$ & $2 / 10$ \\
\hline PT & 18 & 18 & 15 & 18 & 23 & 20 & 20 & 19 & 17 & 18 & 20 & 22 & 21 & 21 \\
\hline PMDB & 11 & 10 & 9 & 9 & 10 & 10 & 11 & 9 & 8 & 8 & 8 & 7 & 8 & 8 \\
\hline PFL & 6 & 8 & 9 & 5 & 5 & 5 & 5 & 4 & 4 & 3 & 4 & 3 & 4 & 4 \\
\hline PSDB & 4 & 3 & 4 & 4 & 5 & 4 & 4 & 5 & 4 & 3 & 3 & 3 & 3 & 4 \\
\hline Outros & 8 & 8 & 6 & 7 & 4 & 5 & 8 & 7 & 6 & 5 & 6 & 6 & 6 & 5 \\
\hline $\begin{array}{l}\text { Sem } \\
\text { Preferência }\end{array}$ & 52 & 53 & 58 & 57 & 53 & 56 & 52 & 56 & 61 & 63 & 59 & 58 & 57 & 58 \\
\hline
\end{tabular}

Fonte: Datafolha

A tabela acima mostra que a identificação partidária é baixa no Brasil. Os números revelam que o percentual de indivíduos sem preferência por um partido é majoritário na realidade política nacional, com média de 56,6\% no período. A análise da tabela revela, ainda, que o PT é o partido com maior número de adeptos, como pode ser observado em todas as sondagens. O PT inicia o ano eleitoral com $18 \%$ da preferência, atinge o ápice em 14 de maio, com $23 \%$ das preferências, e termina as eleições com apoio de $21 \%$ do eleitorado. Outro fato curioso é o percentual declarado para o PSDB, cuja média é inferior a 4\%. Para um partido que comandava o país há dois mandatos, é surpreendente encontrá-lo como o menor partido entre os quatro maiores do país. 
O Gráfico 5 abaixo procura mostrar a correlação entre a preferência partidária pelo $\mathrm{PT}$ e o voto em Lula:

\section{Gráfico 5: Evolução do voto espontâneo, segundo preferência partidária (PT)}

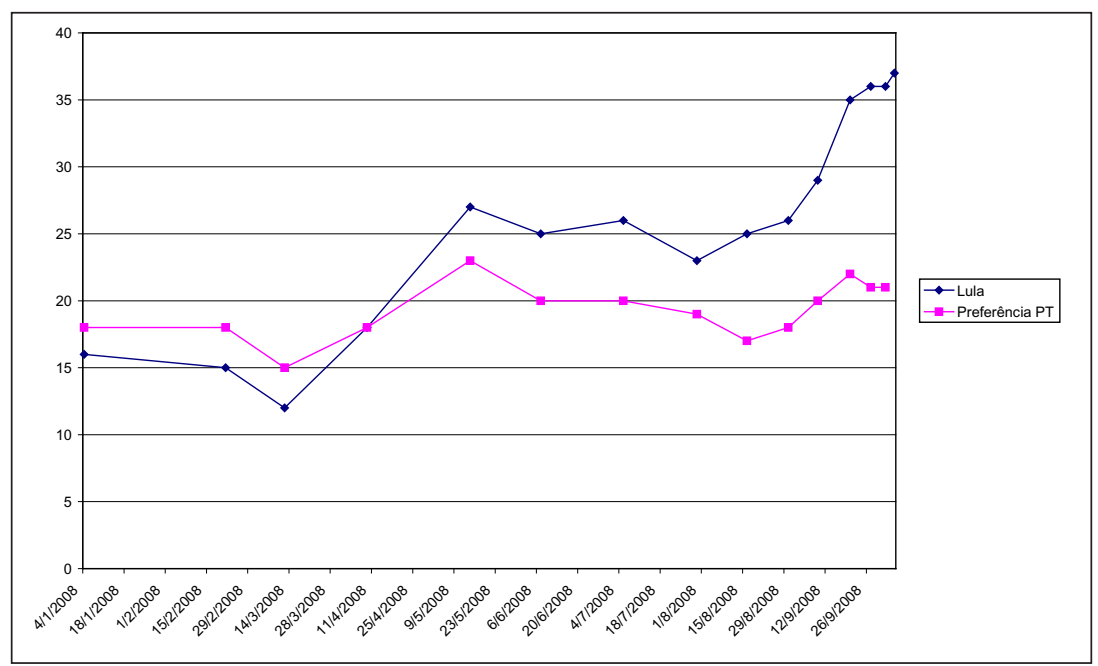

Fonte: Relatórios Datafolha.

Obs.: As datas se referem aos dias em que o Datafolha fez trabalho de campo sobre a intenção de voto dos candidatos durante a campanha de 2002 .

O exame das linhas do gráfico sugere existir correlação entre a preferência partidária declarada pelo PT e o voto em Lula. Podemos notar que o voto espontâneo tende a crescer conforme aumenta a identificação dos eleitores com o partido do candidato. $\mathrm{O}$ teste de regressão, exposto na Tabela 2 a seguir, confirma a expectativa. $O$ coeficiente encontrado $(b=0,773$, $\mathrm{p}<0,1)$ confirma a hipótese segundo a qual a preferência partidária afeta de maneira contundente a intenção de voto, como salientado anteriormente (Downs, 1957; Campbell, 1960).

Por fim, decidimos testar o modelo estatístico final do voto dado a Lula. Fizemos uma regressão que incluiu como variáveis regressoras o saldo da mídia, a adesão ao establishment, a avaliação negativa do governo Fernando Henrique e a preferência declarada pelo PT. Os números indicam que o modelo testado é explicativo do ponto de vista estatístico, mas apenas as variáveis "adesão ao establishment" e "preferência partidária" mostraram ser 
significativas. O saldo da mídia e a avaliação negativa do governo Fernando Henrique, embora sejam significativas quando analisadas isoladamente, perdem força explicativa ao lado de outros controles.

Tabela 2: Evolução do voto espontâneo em Lula, segundo cobertura da mídia, avaliação negativa de Fernando Henrique e preferência partidária (PT)

\begin{tabular}{lccccc}
\hline & $\begin{array}{c}\text { Lula } \\
\text { (b) }\end{array}$ & $\begin{array}{c}\text { Lula } \\
(\mathrm{b})\end{array}$ & $\begin{array}{c}\text { Lula } \\
(\mathrm{b})\end{array}$ & $\begin{array}{c}\text { Lula } \\
(\mathrm{b})\end{array}$ & $\begin{array}{c}\text { Lula } \\
(\mathrm{b})\end{array}$ \\
\hline Mídia & $0,575^{*}$ & & & & $-0,058$ \\
& $(0,040)$ & & & & $(0,782)$ \\
Adesão ao establishment & & 0,633 & & & $0,027^{*}$ \\
FHC Péssimo & & $(0,020)$ & & & $(1,123)$ \\
Preferência (PT) & & & $0,609^{*}$ & & $-0,577$ \\
R & & & $(0,035)$ & & $(0,115)$ \\
F & & & & $0,773^{* *}$ & $0,786^{* *}$ \\
& 0,330 & 0,401 & 0,371 & 0,598 & 0,934 \\
$\mathrm{~N}$ & $5,421^{*}$ & $7,351^{*}$ & $5,906^{*}$ & $17,845^{* *}$ & $21,086^{* *}$ \\
& $(0,40)$ & $(0,020)$ & $(0,035)$ & $(0,001)$ & $(0,001)$ \\
\hline
\end{tabular}

$* \mathrm{p}<0,5 \% ; * * \mathrm{p}<0,1 \%$

\section{Conclusões}

Existem duas linhas metodológicas básicas para investigar os efeitos das campanhas sobre a decisão do voto. A primeira consiste em adotar uma perspectiva contextual, compilando toda a informação possível sobre o contexto da campanha. Estes estudos recorrem, por exemplo, às declarações dos candidatos e à cobertura da imprensa e a partir desses dados procuram realizar uma aproximação entre o resultado da eleição e os aspectos levantados durante o período do experimento.

O segundo método, filiado à tradição de pesquisa norte-americana, tem como base a análise de dados colhidos em estudos de panel, experimentos controlados e, principalmente, de surveys elaborados com amostras representativas da população. O objetivo principal deste enfoque é utilizar ferramentas estatísticas rigorosas a fim de compreender a relação existente entre a comunicação política, as características dos eleitores e as suas preferências eleitorais. O estudo de Lazarsfeld, Berelson e Gaudet (1944), realizado no condado de Eire, Estados Unidos, é um exemplo. 
No caso do estudo que nos ocupou este artigo, a busca da relação entre campanha eleitoral e preferência política se aproxima da primeira linha de investigação. Ela tem a desvantagem de não levar em consideração dados individuais dos eleitores, importantíssimos se tivermos a intenção de compreender de maneira adequada o papel das campanhas. Por outro lado, é um método relativamente simples de detectar possíveis influências das campanhas no comportamento político dos indivíduos, sobretudo nos momentos eleitorais, quando o eleitor é chamado para depositar seu voto numa das opções oferecidas. Os achados deste artigo demonstram que a metodologia empregada tem validade empírica e merece ser testada em outras oportunidades.

Apesar de o efeito campanha, representado aqui pela cobertura da imprensa, ter perdido poder explicativo quando associado a outras variáveis, não podemos descartar de imediato seu potencial como um dos fatores explicativos do voto. Se refrescarmos a memória sobre a campanha de 2002, veremos que a candidatura Ciro Gomes (PPS) ruiu no momento em que foi mais atacado pela imprensa, que o chamava constantemente de destemperado e chegou até a compará-lo ao ex-presidente Fernando Collor, cassado num processo de impeachment sob a acusação de corrupção.

No caso do candidato Lula, pudemos observar que seus índices de intenção de voto cresceram à medida que a linha editorial dos jornais passou a investir numa pauta de caráter mais positivo. Não queremos dizer com isso que Lula não teria vencido as eleições se a imprensa continuasse a atacá-lo. As eleições de 2006, já estudada por muitos pesquisadores, ${ }^{2}$ mostraram que o impacto da cobertura eleitoral tem limites na formação da opinião pública. $\mathrm{O}$ que este estudo tentou mostrar é que, no caso das eleições de 2002, a reviravolta na cobertura eleitoral foi um fenômeno que ajudou Lula em diversos aspectos, entre os quais destaco um clima editorial mais ameno e em consonância com a imagem do "Lulinha paz e amor".

\section{Referências}

ALBUQUERQUE, Afonso de. Aqui você vê a verdade na TV: a propaganda política na televisão. Niterói: MCII/UFF, 1999.

ALDÉ, Alessandra. As eleições presidenciais nos jornais. Alceu Revista de Comunicação, Cultura e Politica, v. 3, n. 6, 2003.

BORBA, Felipe. Razões para a escolha eleitoral: a influência da campanha política na decisão do voto em Lula durante as eleições presidenciais de 2002. Dissertação (Mestrado em Ciências Políticas) - Iuperj, Rio de Janeiro, 2005.

\footnotetext{
2 Entre os quais, destaco o estudo de Figueiredo, Aldé e Mendes (2007) e Coimbra (2007).
} 
CAMPBELL, Angus; CONVERSE, Philip; MILLER, Warren e STOKES, Donald. The American voter. New York: John Wiley \& Sons, 1960.

COIMBRA, Marcos. A mídia teve algum papel durante o processo eleitoral de 2006. In: LIMA, Venício (Org.). A mídia nas eleições de 2006. São Paulo: Editora Fundação Perseu Abramo, 2007. p. 187-210.

COMSTOCK, George; SCHARRER, Erica. The psychology of media and politics. California: Elsevier Academic Press, 2005.

DALTON, Russell. The decline of party identification. In: RUSSEL, Dalton; MARTIN Wattenberg (Orgs.). Parties without partisans: political change in advanced industrial democracies. Oxford: Oxford University Press, 2000. p. 19-36.

DOWNS, Anthony. An economic theory of democracy. New York: Haper and Collins, 1957.

FIGUEIREDO, Marcus. A decisão do voto. São Paulo: Idesp/Sumaré, 1991.

FIGUEIREDO, Marcus;ALDÉ,Alessandra. Intenção de voto epropagandapolitica: efeitos e gramáticas da propaganda eleitoral. VI Lusocom, Covilhã, Portugal, abr. 2004.

FIGUEIREDO, Marcus; ALDÉ, Alessandra; MENDES, Gabriel. Imprensa e eleições presidenciais: natureza e conseqüências da cobertura das eleições de 2002 e 2006. In: LIMA, Venício (Org.). A mídia nas eleições de 2006. São Paulo: Editora Fundação Perseu Abramo, 2007. p. 65-88.

FIORINA, Morris. Retrospective voting in American national elections. New Haven: Yale University Press, 1981.

HOLBROOK, Thomas. Do campaigns matter? London: Sage Publications, 1996.

JORGE, Vladimir Lombardo. Os meios de comunicação de massa nas campanhas eleitorais. Revista Comunicação e Política, Rio de Janeiro, v. 4, n. 1, p. 126-133, jan. 1997.

KEY Jr. V. O. The responsible electorate: rationality in presidential voting (1936-1960). 3. ed. Cambridge: Harvard University Press, 1966.

KLEINNIJENHUIS, Jan; RIDDER, Jan A. Issue news and electoral volatility: a comparative analysis of media effects during the 1994 election campaign in Germany and Netherlands. European Journal of Political Research. v. 33, p. 413-437, maio 1998.

LAZARSFELD, Paul; BERELSON Bernard; GAUDET Hazel. The people's choice: how the voter makes up his Mind in a presidential campaign. New York: Columbia University Press, 1944.

LIPPMANN, Walter. Public opinion. New York: Free Press Paperbacks, 1922.

VREESE, Claes H.; SEMETKO, Holli. News matters: influences on the vote in Danish 2000Euroreferendumcampaign.EuropeanJournalofPoliticalResearch.v.43,p.699-722, ago. 2004.

WATTENBERG, Martin. The rise of candidate-centered politics: presidential elections of 1980's. Cambridge: Massachusetts: Harvard University Press, 1991. 